\title{
COVID-19 and its Psychological Impact among General Population - A Questionnaire Survey
}

\section{Joseph George Kallivayaliil, ${ }^{1}$ Preetha S2 ${ }^{2}$ Kavitha S ${ }^{3}$, Lavanya Prathap ${ }^{4}$}

Section: Healthcare

Sci. Journal Impact

Factor: 6.1 (2018)

ICV: 90.90 (2018)

(c) (3) (8)

Copyright@IJCRR

\author{
'Department of Physiology, Saveetha Dental College and Hospitals, Saveetha University, Saveetha Institute of Medical and Technical \\ Sciences, Chennai, India; 'Senior Lecturer, Department of Physiology, Saveetha Dental college and Hospitals, Saveetha University, \\ Saveetha Institute of Medical and Technical Sciences, Chennai, India; ${ }^{3}$ Lecturer, Department of Biochemistry, Saveetha Dental College \\ and Hospitals, Saveetha Institute of Medical and Technical Sciences, Saveetha University, Chennai, India; ${ }^{4}$ Assistant Professor, Depart- \\ ment of Anatomy, Saveetha Dental College and Hospitals, Saveetha Institute of Medical and Technical Sciences, Saveetha University, \\ Chennai, India.
}

\section{ABSTRACT}

Introduction: As an infectious disease, COVID-19 is successfully being contained globally by instituting widespread quarantine measures. The 2019 Novel Coronavirus disease (COVID-19) epidemic is a public health emergency of international concern and poses a challenge to the psychological resilience, economy, and social life of people. Research data are needed to develop evidence-driven strategies to reduce adverse psychological impacts, economic recession, and disturbance of social life during the epidemic. The main aim of the study was to assess the psychological impact and effects due to COVID-19 among the general population.

Material and Methods: A self-administered questionnaire was prepared to analyze the psychological impact of quarantine on the individuals during this period. A cross-sectional study was conducted in a sample of 100 individuals and data was collected and analyzed using SPSS software. Chi-square test was done and a P-value of $<0.05$ was said to be statistically significant.

Result and Discussion: $71.3 \%$ of the respondents have heard of the term COVID-19 while $28.7 \%$ of the respondents have not heard. $52.5 \%$ of the respondents were under stress during this period while $47.5 \%$ of the respondents were not under any stress during this period.

Conclusion: Hence, the study shows us that $70 \%$ of the respondents' mental health was affected during this period.

Key Words: COVID 19, Quarantine, Population, Psychological effects, Stress, Pandemic.

\section{INTRODUCTION}

Coronaviruses are a large family of viruses, some of which cause illness in people. On February 11, 2020, the World Health Organization named the outbreak as Coronavirus disease (COVID-19). China adopted quarantine for 14 days to prevent transmission of COVID-19. The number of deaths increased rapidly across the world. With more than 118,000 cases and 4291 deaths in 114 countries, COVID-19 became a major concern for global health ${ }^{1}$. During December 2019, coronavirus disease outbreak has been seen in many nations as human beings who've doubtlessly come into contact with the contamination to isolate themselves at domestic or in a committed quarantine facility. Decisions on how to manage quarantine should be based on available evidence ${ }^{2}$. Quarantine and isolation are public health measures used for pre- venting the transmission of infectious diseases among individuals and communities. Quarantine became the fewest known measures to protect lives and cities during a deadly disease became one of the fewest known measures ${ }^{3}$. Italy has the highest number of deaths, which announced a nationwide quarantine to address COVID-19. Although quarantine and isolation are adopted for protecting the physical health from infectious diseases, it is also important to consider the mental health of the people experiencing such restrictions. The people quarantined in earlier outbreaks of diseases have reported adverse mental health problems during the quarantine period. The isolation imposed with the aid of quarantine regularly leaves humans feeling that they have no control over the situation. They also feel cut off from the rest of the world and unable to perform their usual duties which can be related to the people under quarantine. The brain chemicals

\section{Corresponding Author:}

Dr. Preetha S, Senior Lecturer, Department of Physiology, Saveetha Dental college, Saveetha University, Saveetha Institute of Medical and Technical Sciences, 160, Poonamallee High Road, Chennai 600077, Tamilnadu, India; Phone: 8608566435; Email: preethas.sdc@saveetha com

ISSN: 2231-2196 (Print)

Received: 22.07 .2020
ISSN: $0975-5241$ (Online)

Revised: 24.08 .2020
Accepted: 18.09 .2020
Published: 20.10 .2020 
connected with deep sleep are the same ones that tell your body to stop the production of stress hormones. As a result, people psychologically affected due to this pandemic don't sleep well the body keeps pumping out those hormones and eventually the next day the body feels more stressed ${ }^{4}$. When the body is stressed, muscles tense up and can have various actions on the emotional stability of an individual ${ }^{5}$. Chronic stress can lead to the development of cardiovascular diseas$\mathrm{es}^{6}$. We have studied awareness on various topics ${ }^{7-16}$ and the present study assesses the psychological effects during this pandemic. Hence it is important to empower the decisionmakers to adopt evidence and protect the physical and mental health during outbreaks of these infectious diseases. The main aim of the study was to assess the psychological impact and effects due to COVID-19 among the common people.

\section{MATERIAL AND METHODS}

The survey was conducted among 100 individuals and was approved by the institutional review board. The survey was conducted in an online setting using google forms (https:// forms.gle/UoHcsddPySUNG5S37). A convenience sampling method was used. A questionnaire was prepared which consisted of 10 questions relating to the psychological effects due to Coronavirus. The types of questions were closeended.

\section{QUESTIONNAIRE}

1. Gender

a) Male b) Female

2) Are you aware of COVID -19 and its outbreak.

a) Yes b) No

3) Are you under home quarantine

a) Yes b) No

4) How is your current mental health

a) Good b) Bad

5) What is your marital status

a) Married b) Single c) Single and divorced

6) Do you feel stressed during this period

a) Yes b) No

7) Were you affected by anxiety or discomfort. a) Yes b) No

8) Were you affected by lack of mental peace during this period

a) Yes b) No

9) How have you been feeling during this quarantine

a) Tired b) Depressed c) Scared d) Bored

10) Are you a health care worker during this period

a) Yes b) No

Questionnaire validity checking was done by consulting experts. Data collection and interpretation was done. The statistical analysis was done using SPSS software.

\section{STATISTICAL ANALYSIS}

Chi-square type of analysis was also done to assess the correlation. The results were represented with a pie chart and a bar diagram.

\section{RESULT AND DISCUSSION}

From the survey conducted, the following results were obtained. (Fig 1) $71.3 \%$ were Male while $28.7 \%$ Female. (Fig 2) $71.3 \%$ of the participants have known the symptoms of COVID-19 while $28.7 \%$ of the participants were not aware of the symptoms. (Fig 3) $52.5 \%$ of the participants were under home quarantine while $47.5 \%$ of the participants were not under home quarantine. (Fig 4) $62.8 \%$ of the respondents have good mental health during this period while $31.3 \%$ of the respondents have poor mental health. Activities done during quarantine, $42.5 \%$ of them prefer alone time, $21.3 \%$ of the respondents spend time on electronics $25 \%$ of the respondents spend time with family, (Fig 5) 65\% respondents are married, $35 \%$ respondents are single while $5 \%$ individuals are single and divorced. (Fig 6) $77.5 \%$ of the respondents were not stressed during this period while $33.2 \%$ was affected by stress. (Fig 7) $63.7 \%$ of the individuals experienced anxiety or discomfort during this period while $36.3 \%$ of the individuals lack mental peace during this period while $30.8 \%$ experience mental peace. (Fig 8) 55.5\% of respondents show that they lack mental peace during this period while $25.5 \%$ don't feel the same. (Fig 9) $32.3 \%$ of the respondents feel bored during quarantine, while $22 \%$ feel tired, $24 \%$ feel depressed $5 \%$ feel scared. (Fig 10) The graph depicts the association between gender and the respondents who have heard of the term COVID using Chi-square test. P-value is 0.01 less than 0.05 which is statistically significant which shows that males have heard the term COVID-19 more than the females. (Fig 11) The graph depicts the association between gender and the mental health of the respondents using Chi-square test. P-value was 0.029 , which was less than 0.05 which is statistically significant which shows that Male have more mental health problems than females. (Fig 12) The graph depicts the association between gender and the daily activities followed by people during the quarantine using Chi-square test. P-value was less than 0.05 which is statistically significant which shows that females are more stressed during this period than males. (Fig 13) The graph depicts the association between gender and the respondents lacking mental peace during this period using Chi-square test. P-value was less than 0.05 which is statistically significant which shows that males lack mental peace more than females.

In the present study, $71.3 \%$ of the participants have heard of the term COVID -19 and $28.7 \%$ were not aware. Similarly in the study conducted by Sarita Bharadurja et al., $75 \%$ of the participants were aware ${ }^{17} 52.5 \%$ of the participants were 
under home quarantine and $47.5 \%$ are not. Similarly in the study done by Tarun Karla et al., it was found that people under home quarantine experience a high burden of mental disorders, which necessitates integrating psychosocial caste and mental health ${ }^{18}$. In the work done by Suni Jurel et al., $60 \%$ of the participants were under home quarantine ${ }^{19} .77 .5 \%$ of the participants were health care workers while $22.5 \%$ are not, In the study conducted by J Hladwar et al. it shows us that $80 \%$ of the participants were health care workers who have reported various mental problems including emotional exhaust, which may result in suboptimal performance in workplaces ${ }^{20}$ but opposing in the study conducted by Sucvhi Tripathi et al., $85 \%$ of the respondents were non-health care workers while $15 \%$ were health care workers ${ }^{21} 69.2 \%$ participants said Yes for experience anxiety or discomfort during this period and $30 \%$ said No.

Similarly in the study by Bharat R et al. $73.9 \%$ of the participants said yes for experiencing anxiety or discomfort during this lockdown ${ }^{22} 57.5 \%$ of the respondent's family relatives are affected by COVID -19 while $42.5 \%$ are not . Similarly in the study done by Rheema Kumaniet et al, most of the responses family relatives and closed ones were affected by COVID -19. In our present study, $45 \%$ of the respondents are away from their family and $55 \%$ are with their family ${ }^{23}$. Similarly in the study done by Kaudsha K Agarawall et al., $55 \%$ of the respondents are with their family during this quarantine and suffer from no mental health problem, like anxiety and stress disorders ${ }^{24} \mathrm{~A}$ study evaluated the mental health status of 398 parents of children who experienced mental problems and $25 \%$ of the parents experience posttraumatic disorder. ${ }^{25}$ Another study assesses the mental health status of individuals who were isolated during COVID epidemic found that the prevalence of anxiety and feeling of anger symptoms among the quarantined individuals. The research shows that stress can cause the disease independent of changes in body weight, food intake, impairs normal liver function, and can cause non-alcoholic fatty liver disease ${ }^{26}$. It also shows us that woman infertility problems are reported elevated due to stress and anxiety which are high during this pandemic ${ }^{27}$. In a study conducted at Faridabad to find out the relation between academic anxiety and mental health, the study proves that there is a significant relationship between academic anxiety and the mental health of the students. The limitation of the study was a large sample population and further study can be controlled among a small scale to give a more accurate result measuring the awareness.

\section{CONCLUSION}

$70 \%$ of the respondent's mental health was affected during this quarantine. This indicates a need for a more systematic and longitudinal assessment of the psychological needs of the population, which can help the government in formulating holistic interventions for affected individuals. Further, it was suggested that to cope with COVID-19 lockdown stress, people should keep themselves busy in physical activities, religious activities, and social work.

\section{ACKNOWLEDGEMENT}

This research was done under the supervision of the Department of Research of Saveetha Dental College and Hospitals. We sincerely show gratitude to the Institution who provided insight and expertise that greatly assisted the research.

\section{Conflict of Interest}

The author has none to declare

\section{REFERENCES}

1. Meehan, C. D., and H. Markel. 2009. "Cholera, Historical." Encyclopedia of Microbiology. 2009.

2. Guttmacher, Laurence B. 1990. "Treatments of Psychiatric Disorders: A Task Force Report of the American Psychiatric Association-Washington, D.C., American Psychiatric Association, 1989, 4 Volumes, 3,068 Pages, \$275.” Psychiatric Services 1990.

3. Hench, Atcheson L. 1938. "Corbins and Nicholsons: A Preliminary Note." American Speech. https://doi org/10.2307/451380.1938.

4. Ilankai, RG Devi, Rj, I., and G. D. R.. Role of environmental factors on sleep patterns of different age groups: a surveybased study. Asian Journal of Pharmaceutical and Clinical Research. 2016. Vol. 9, no. 6: pp. 124-6, doi: 10.22159/ajpcr.2016. v9i6.13832.

5. Harsha, L., Priya, J., Shah, K.K., Reshmi, B, Systemic approach to management of neonatal jaundice and prevention of kernicterus, 2015; Research Journal of Pharmacy and Technology Vol 8(8), pp : 1087-1092.

6. Renuka, S., Sethu, G. Regeneration after myocardial infarction. Research Journal of Pharmacy and Technology. 2015;8(6): 738741.

7. Dave, Preetha S. Pathogenesis and Novel Drug for Treatment of Asthma-A Review, Research Journal of Pharmacy and technology (2016) 9 (9), 1519-5(2016).

8. Abigail, Jothi Priya, A., Devi, G.Evaluation of muscular endurance among dentists, Indian Journal of Public Health Research and Development, 2019, 10, 10, 258 - 261.

9. David, Jothi Priya, A., Devi, G,Physical fitness among the dental physician, dental undergraduates and postgraduates students, Indian Journal of Public Health Research and Development, 2019, $10,10,223-226$

10. Shruthi, M., Preetha, S, Effect of simple tongue exercises in habitual snorers; 2018; Research Journal of Pharmacy and Technology ;vol 11( 8); pp : 3614-3616

11. Samuel, A.R., Devi, G, Geographical distribution and occurrence of endemic goitre, 2015 Research Journal of Pharmacy and Technology, Vol 8(8), pp 973-978.

12. Gayatri Devi, R., Jothi Priya, A, A survey study on causes, treatment and prevention of onychocryptosis, Research Journal of Pharmacy and Technology 10(8)807-811.

13. Gayatri Devi, R., Sethu, G, Evaluation of adenoids by oronasal and nasal spirometry, 2018 ; Asian Journal of Pharmaceutical and Clinical Research, Vol 11(10) PP - 272-274. 
14. S., Sethu, V.G. Acupuncture and lower back pain. Research Journal of Pharmacy and Technology. 2015; 8(8): 991-993.

15. McBain, Ryan K., Rebecca L. Collins, Eunice C. Wong, Joshua Breslau, Mathew S. Cefalu, Elizabeth Roth, and M. Audrey Burnam. 2020. "Mental Health Services and Personal Recovery in California: A Population-Based Analysis.” Psychiatric Services 71 (6): 580-87.

16. Burke, Gerald F. 1983. "Caring for the Medically Ill Psychiatric Patient On a Psychiatric Unit.” Psychiatric Annals. https://doi. org/10.3928/0048-5713-19830801-06.

17. Zerbin-Rüdin, Edith. 1987. "Psychiatric Genetics and Psychiatric Nosology." Journal of Psychiatric Research. https://doi. org/10.1016/0022-3956(87)90084-7.

18. Guan X Fu Wei et al. 2020 stress during quarantine. Neumologia Pedi Átrica, 2020 pp 334-454.

19. Thornton, Jacqui. 2020. "Covid-19 Pandemic Has Derailed Progress on Sustainable Development Goals, Says WHO."

20. Risse, Guenter B. 2020. "Glimpses of a Hidden Burden: Hydatid Disease in Eighteenth-Century Scotland." Bulletin of the History of Medicine 79 (3): 534-43.

21. Bhatia, Richa. 2020. "Effects of the COVID-19 Pandemic on Child and Adolescent Mental Health." Current Opinion in Psychiatry, August 2020.

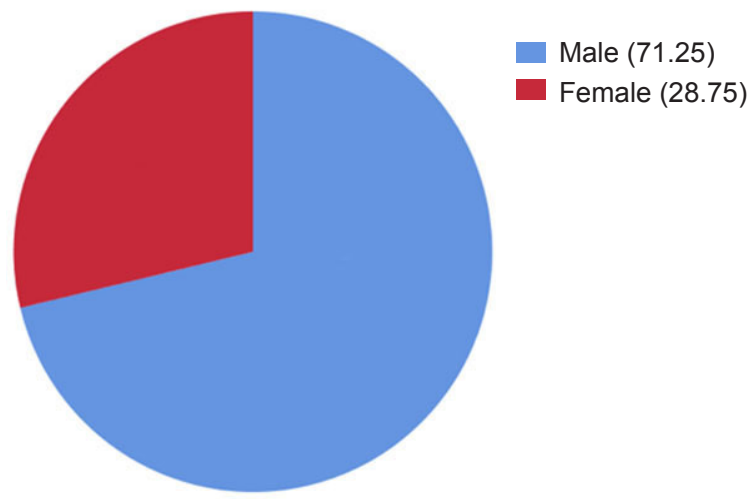

Figure 1: Pie chart showing distribution of study subjects based on gender. $71.3 \%$ of them males and $28.7 \%$ of the respondents were females.

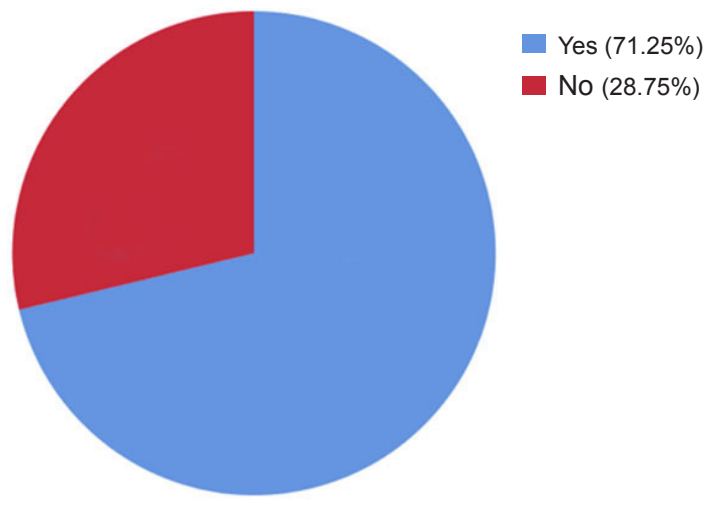

Figure 2: Pie chart showing percentage distribution of awareness of COVID -19 and its outbreak. $71.3 \%$ responded that they were aware and $28.7 \%$ responded that they were not aware about the epidemic.
22. Dong, Weizhen. 2020. "Beyond SARS: Ethnic Community Organization's Role in Public Health - a Toronto Experience." Promotion \& Education.

23. Herman Jp, Maroun M, Richter-levin G 2015 Stress Related Disorders pp-205-345.

24. McBain, Ryan K., Rebecca L. Collins, Eunice C. Wong, Joshua Breslau, Mathew S. Cefalu, Elizabeth Roth, and M. Audrey Burnam. 2020. "Mental Health Services and Personal Recovery in California: A Population-Based Analysis.” Psychiatric Services 71 (6): 580-87.

25. Burke, Gerald F. 1983. "Caring for the Medically Ill Psychiatric Patient On a Psychiatric Unit." Psychiatric Annals. https://doi. org/10.3928/0048-5713-19830801-06.

26. Choudhari, S., Jothipriya, A.Non-alcoholic fatty liver disease, Research Journal of Pharmacy and Technology 2016, 9,10,1782 -1785 .

27. Baheerati, M.M., Gayatri Devi, R, Obesity in relation to infertility, 2018, Research Journal of Pharmacy and Technology Vol 11 (7), pp-3183-3185.

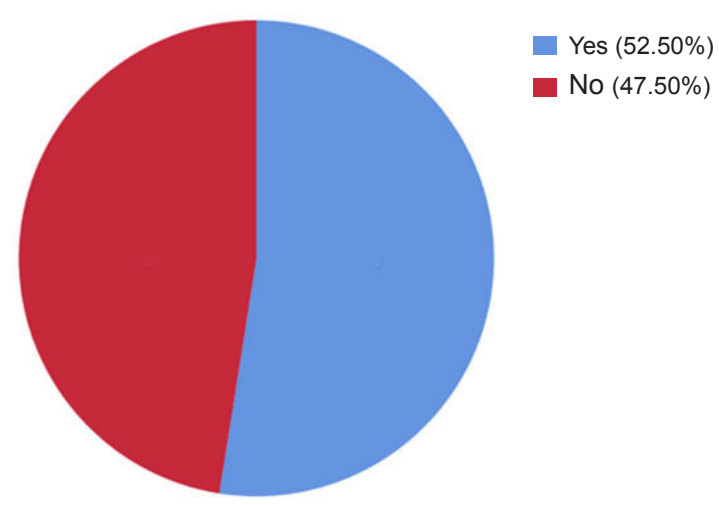

Figure 3: Pie chart showing percentage distribution of respondents under home quarantine. $52.5 \%$ responded Yes, they were under home quarantine and $47.5 \%$ responded No.

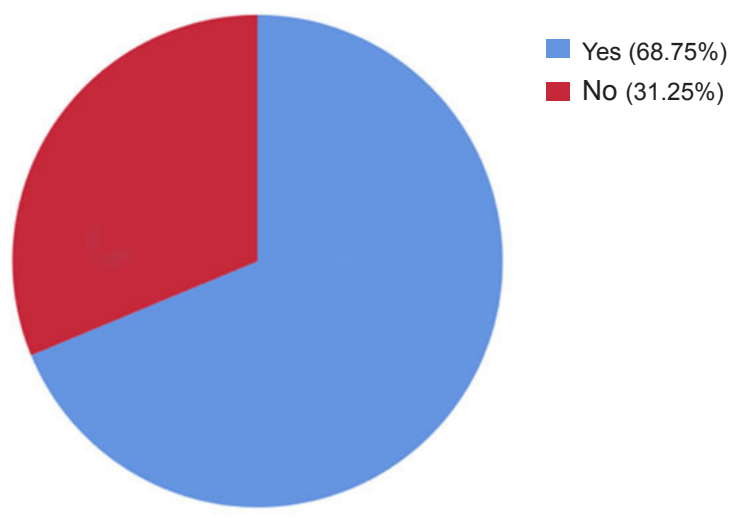

Figure 4: Pie chart showing percentage distribution of respondents based on their current state of mental health. $68.75 \%$ of respondents were mentally healthy and $31.3 \%$ of respondents were not mentally healthy. 


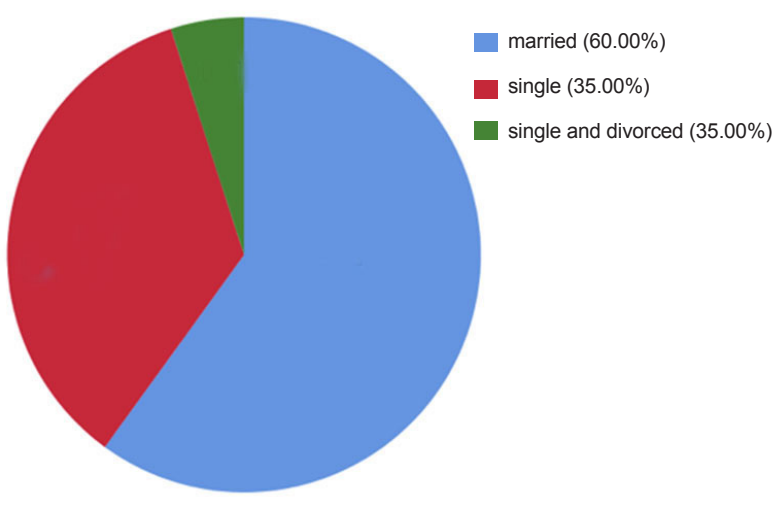

Figure 5: Pie chart showing percentage distribution of marital status of respondents. $60 \%$ Responded as married $35 \%$ were single and $5 \%$ as single and divorced.

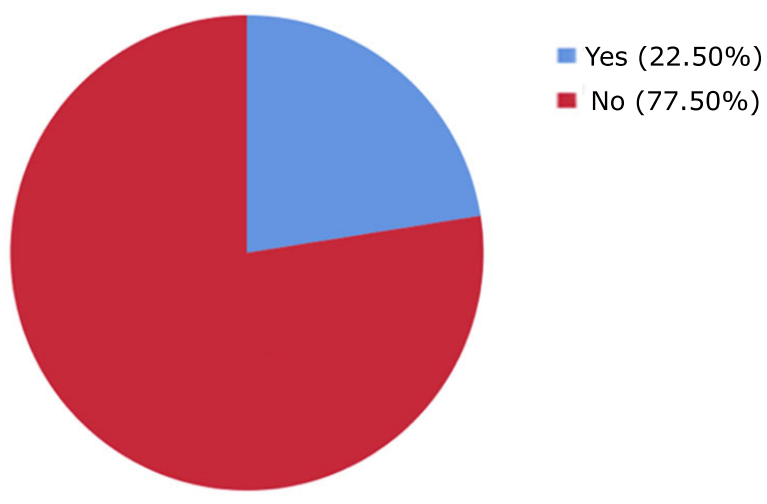

Figure 6: Pie chart showing percentage distribution of stress affecting the respondents. $77.5 \%$ responded they were not stressed and $22.5 \%$ responded, they were stressed.

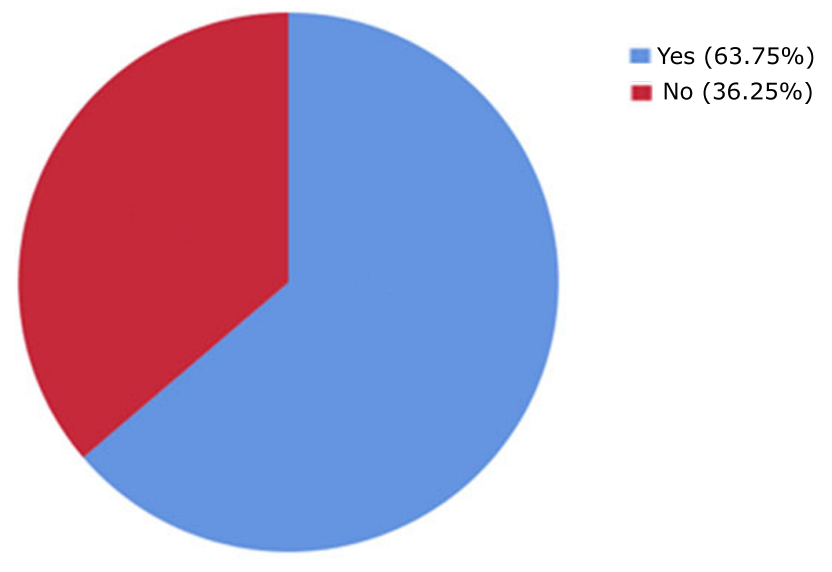

Figure 7: Pie chart showing percentage distribution of respondents affected by anxiety or discomfort. $63.7 \%$ responded they had anxiety and discomfort and $36.3 \%$ responded No

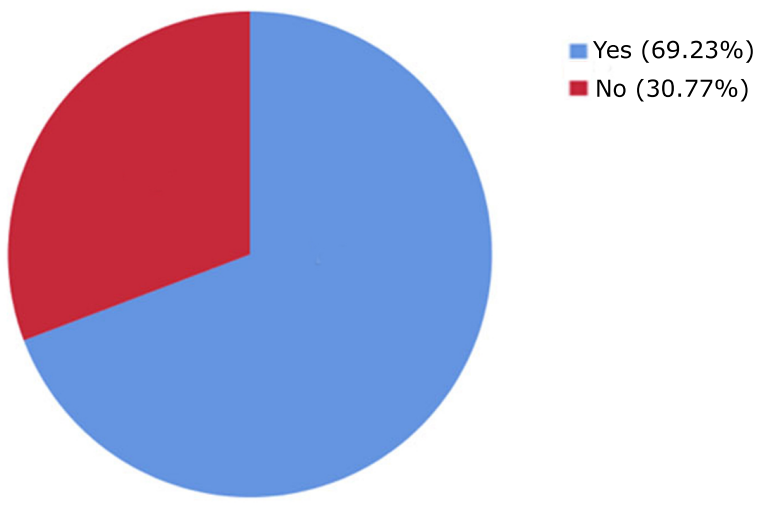

Figure 8: Pie chart showing percentage distribution of respondents affected by lack of mental peace. $55.5 \%$ experienced lack of mental peace and, $25.5 \%$ responded No such thing.

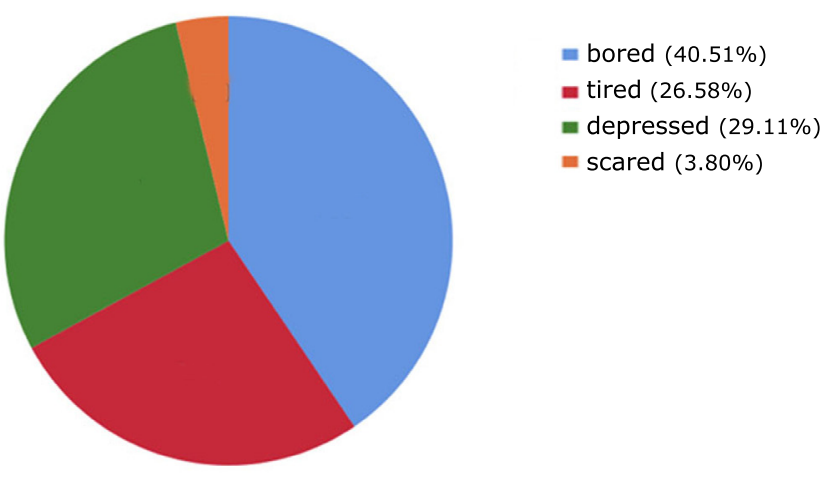

Figure 9: Pie chart showing percentage distribution of feeling of the respondents during this quarantine period. $40.51 \%$ were bored $26.58 \%$ were tired $29.11 \% \%$ were depressed, $3.8 \%$ were scared.

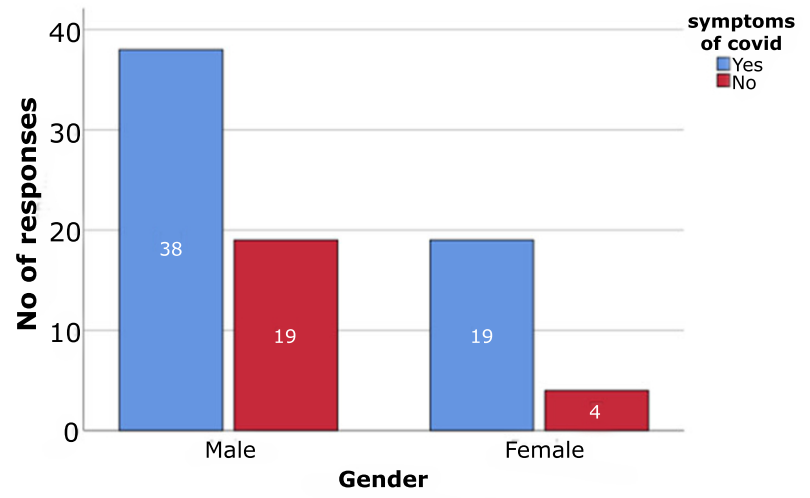

Figure 10: The bar graph depicts the association between gender and the respondent's awareness on COVID 19 and its effects. $X$ axis represents gender and the $Y$ axis represents the number of respondents. Blue bar denotes who are aware of the symptoms and red bar denotes who are not aware. The males were more aware of COVID 19 and its symptoms than females. The chi square test was analyzed and the $P$ value $=0.01,(p>0.05)$ and is statistically significant. 


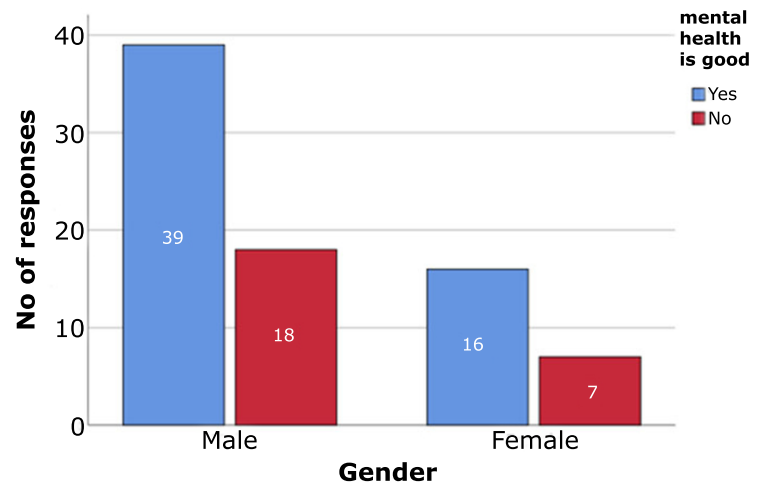

Figure 11: The bar graph depicts association between gender and the mental health of the respondents during Covid lockdown. $X$ axis represents the gender of the respondents and $Y$ axis represents the no of respondents. Blue bar represents yes and Red bar represents no. The males have better mental health than females. The chi square test was analysed $P$ $=0.045(p>0.05)$ which is statistically significant.

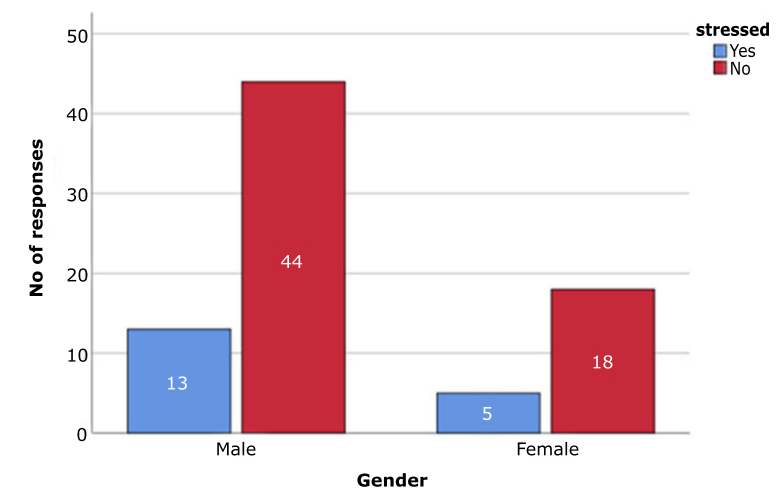

Figure 12: This graph depicts the association between gender and the stress during COVID -19 lockdown period. $X$ axis represents the gender of the respondents, $Y$ axis represents the number of respondents who feel stressed during COVID -19 lockdown. Blue bar represents the respondents who were stressed during the COVID -19 lockdown, Red bar represents the respondents who were not stressed. The males were more stressed during the lockdown than females. The chi square test was analysed $P$ value $=0.032(p>0.05)$ which is statistically significant.

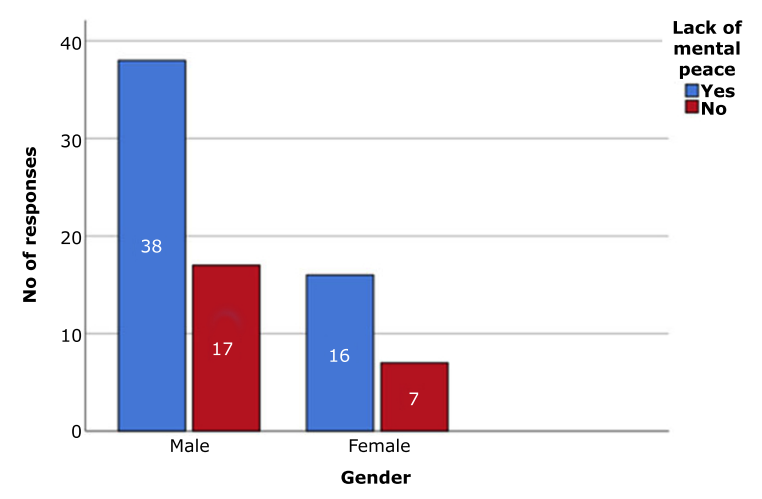

Figure 13: This graph depicts association between gender and the respondents lacking mental peace during the COVID-19 lockdown period. $X$ axis represents the gender of the respondents $Y$ axis represents the respondents who lack mental peace. Blue bar represents the respondents lacking mental peace, Red bar represents the respondents who have mental peace through the COVID -19 lockdown period. The males lacked mental peace more than the females. The chi square test was analysed $P$ value $=0.033(p>0.05)$ which is statistically significant. 